\title{
(6) OPEN ACCESS \\ Assessment of the European Union's illicit trade agreements with the four major Transnational Tobacco Companies
}

\author{
Luk Joossens, ${ }^{1}$ Anna B Gilmore, ${ }^{2}$ Michal Stoklosa, ${ }^{3}$ Hana Ross ${ }^{4}$
}

\begin{abstract}
${ }^{1}$ Association of the European Cancer Leagues \& Tobacco Control Expert, Foundation Against Cancer, Brussels, Belgium

2Department for Health, University of Bath and UK Centre for Tobacco and Alcohol Studies, Bath, UK ${ }^{3}$ Economic and Health Policy Research, American Cancer Society, Atlanta, USA ${ }^{4}$ University of Cape Town, Cape Town, South Africa
\end{abstract}

\section{Correspondence to} Dr Luk Joossens, Association of European Cancer Leagues, Chaussée de Louvain 479, Brussels B-1030, Belgium; luk@europeancancerleagues. org

Received 24 December 2014 Accepted 4 May 2015 Published Online First 28 May 2015

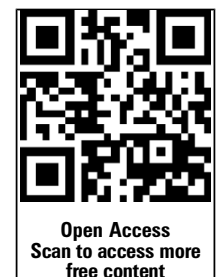

\section{ABSTRACT}

To address the illicit cigarette trade, the European Union (EU) has signed agreements with the four major Transnational Tobacco Companies (TTCs) that involve establishing extensive systems of cooperation. All agreements foresee two types of payments: annual payments (totalling US\$ 1.9 billion over 20 years) and supplementary seizure payments, equivalent to $100 \%$ of the evaded taxes in the event of seizures of their products. While limited by the fundamental lack of transparency in this area, our analysis suggests that these agreements have served largely to secure the TTCs' interests and are threatening progress in tobacco control. The seizure payments are paltry and a wholly inadequate deterrent to TTC involvement in illicit trade. Despite the agreements, growing evidence indicates the TTCs remain involved in the illicit trade or are at best failing to secure their supply chains as required by the agreements. The intention of the seizure-based payments to deter the tobacco industry from further involvement in the illicit cigarette trade has failed because the agreements contain too many loopholes that provide TTCs with both the incentive and opportunity to classify seized cigarettes as counterfeit. In addition, the shifting nature of cigarette smuggling from larger to smaller consignments often results in seizures that are too small to qualify for the payments. Consequently, the seizure payments represent a tiny fraction of the revenue lost from cigarette smuggling, between 2004 and 2012, 0.08\% of the estimated losses due to illicit cigarette trade in the EU. Our evidence suggests the EU should end these agreements.

\section{INTRODUCTION}

A key element of the European Union's (EU) policy to combat the illicit cigarette trade is its collaboration with the tobacco industry. ${ }^{1}$ The EU has signed illicit trade agreements with the four major Transnational Tobacco Companies (TTCs): in 2004 with Philip Morris (PM), which includes Philip Morris International (PMI); in 2007 with Japan Tobacco International (JTI); and in 2010 with British American Tobacco (BAT) and Imperial Tobacco Limited (ITL). ${ }^{2-5}$ At least three of the four agreements were signed to settle or avoid legal disputes between the companies and the EU in relation to involvement of those companies in cigarette smuggling. All established extensive systems of cooperation between the TTCs and the EU at a time when the broader regulatory trend was one of exclusion.

Since the Agreement with PMI ends in July 2016, negotiations to explore a possible extension are currently underway. ${ }^{6}$ This article therefore aims to inform those negotiations by examining the effectiveness of these agreements. It begins by outlining the background to the agreements including the history of TTC involvement in the illicit cigarette trade globally and in the EU, and the development and nature of these agreements. The aim of this paper is to critically assess the agreements and their execution in the EU. We also discuss the implications of these agreements for tobacco control.

\section{THE HISTORY OF THE TOBACCO INDUSTRY'S} INVOLVEMENT IN THE ILLICIT TOBACCO TRADE

Tobacco companies make their profits when they sell to traders, regardless of whether the cigarettes are then sold legally or illegally. ${ }^{7}$ Evidence of the direct and indirect involvement of the tobacco industry in cigarette smuggling is well documented -in internal documents that TTCs were forced to release in the course of litigation, ${ }^{9-14}$ their own admission ${ }^{15}$ and court judgements. ${ }^{16}$ Since 1997, there have been several official investigations and subsequent court cases in different parts of the world (Hong Kong, Canada, Colombia) that have accused the industry of supplying the smuggled cigarettes or at least of being aware of the illegal destination of their products. ${ }^{17-22}$

In the 1990s, American cigarette brands were a key element of the contraband trade in the EU. ${ }^{23}{ }^{24} \mathrm{An}$ EU investigation on smuggling activities started in 1998. It culminated on 3 November 2000, when the EU filed a lawsuit in the US District Court in New York, against PM, RJ Reynolds and Japan Tobacco, which had by then acquired the international division of RJ Reynolds, alleging that these tobacco companies were guilty, in effect, of controlling entire smuggling operations and accusing the companies of "an ongoing global scheme to smuggle cigarettes, launder the proceeds of narcotics trafficking, obstruct government oversight of the tobacco industry, fix prices, bribe foreign public officials and conduct illegal trade with terrorist groups and state sponsors of terrorism". ${ }^{25}$ In 2000 and 2001, 10 EU countries, led by Italy, joined the lawsuit. ${ }^{26}$

Additional allegations were filed by the EU and ten EU governments against RJ Reynolds in the same court in October 2002 on the company's engagement in organised crime, money laundering and narcotics trafficking and in transactions that financed both the Iraqi regime under Saddam Hussein and terrorist groups. ${ }^{27} 28$ While this second lawsuit against RJ Reynolds is still ongoing, ${ }^{29} \mathrm{PM}$ and JTI settled their smuggling disputes with the EU in 2004 and 2007, respectively. ${ }^{4}$ 


\section{AGREEMENTS WITH THE FOUR MAJOR TOBACCO COMPANIES}

In parallel with the legal proceedings, confidential discussions began in late 2001 between the European Commission and PM on a possible agreement to cooperate in combating illicit cigarettes. ${ }^{4}$ In 2004, the EU and 10 Member States dropped the case against PM in exchange for an enforceable and legally binding agreement. A similar agreement settling a legal dispute was concluded with JTI in December 2007. Two additional agreements were signed with BAT in July 2010, and ITL in September 2010. An overview of the main characteristics of the four agreements is presented in table 1 .

Although the agreements with BAT and ITL were not part of a legal settlement, ITL's agreement releases the company from future liability for smuggling, and it is possible that the BAT agreement may serve the same purpose. Alongside the main agreement, ITL signed a parallel agreement (called Mutual Cessation Agreement) that "absolutely, unconditionally and irrevocably fully release and discharge ITL Group Companies and their successors, Agents and Assigns from any and all EU Claims". ${ }^{5}$ A press release from Her Majesty's Revenue and Customs in the UK suggests the BAT agreement has a similar clause noting that "the manufacturers (BAT) are released from any civil claims arising out of past conduct relating to illicit trade" ${ }^{30}$ However, this information is not part of the publicly available BAT-EU agreement. ${ }^{5}$ Three of the four agreements (except with PM) also give TTCs the right to terminate the monetary payments if the agreements fail to meet their "reasonable expectations" of benefit. ${ }^{5}$

The four agreements foresee two types of payments to the European Commission and the Member States: annual fixed payments (see table 1) and supplementary seizure-based payments (see table 2). The fixed payments total 1.9 billion US dollars paid in annuities from 2004 to 2030. PM pays the European Commission and Member States and its lawyers a total of $\$ 1.250$ billion in annual payments (payment of $\$ 1$ billion over 12 years and $\$ 250$ million legal fees). JTI's total of annual payments are $\$ 400$ million over 15 years, BAT's total of annual payments are $\$ 200$ million over 20 years, and ITL's annual payments are $\$ 300$ million over 20 years. These payments are generally considered compensation for the losses incurred through the TTC's smuggling activities. For instance, Italy-a prominent victim of PM smuggling activities-received the largest proportion $(28.62 \%$ of the 1 billion paid by $\mathrm{PM}) .^{31}$

In addition to the annual payments outlined above, a key feature of the agreements is the specification of seizure payments if TTCs fail to control their supply of cigarettes to the illegal market. The companies agreed to make payments equivalent to $100 \%$ of the evaded taxes in the event of any seizures of their genuine products above 50.000 cigarettes in the EU countries that were party to the Agreement. If seizures of their genuine products in the Member States during a year exceed the baseline
Table 2 Cigarette seizure payments in the $\mathrm{EU}$ as a result of agreements with four major tobacco companies

\begin{tabular}{lc} 
Year & Seizure payments (EURO) \\
\hline 2006 & 20289472 \\
2007 & 10342796 \\
2008 & 6922838 \\
2009 & 11178975 \\
2010 & 7754716 \\
2011 & 10098035 \\
2012 & 4141791 \\
$2006-2012$ & 70728624
\end{tabular}

Source: Anna Gilmore-documents obtained via access to documents legislation. ${ }^{38}$

EU, European Union.

amounts defined in the Agreements (originally set at 90 million cigarettes in the PM agreement, 90 million cigarettes in the JTI and ITL agreements and 150 million cigarettes in the BAT agreement), the tobacco companies must pay $500 \%$ of the evaded duties and taxes. ${ }^{5}$ Although these baseline amounts have not yet been reached, the PMI baseline was raised from 90 million cigarettes to 450 million in $2011,{ }^{32}$ substantially reducing the likelihood of PMI, spun off from PM in 2008, ever paying the $500 \%$ penalty.

Some countries earmark the payments to fight illicit cigarette trade, while others direct the funds to the general budget. ${ }^{2}$ All agreements also required TTCs to secure the supply chain through a range of measures, including product marking and tracking and tracing provisions. The agreements are enforceable, but all arbitral proceedings are kept confidential. ${ }^{5}$

\section{ASSESSMENT OF THE AGREEMENTS}

Full evaluation of the agreements is almost impossible, as there are no independent publicly available data on the origins and brands of illicit tobacco products and the size of the illicit market in the EU (personal communication, Corneliu Hoedlmayr, International Relations Officer, OLAF, 6 May 2014). The only publicly available data on the EU illicit cigarette trade over time are data produced by KPMG for the tobacco industry. ${ }^{33}$ The KPMG data have been reviewed elsewhere and although the underlying methodology was commended, significant concerns were raised about the accuracy of the data and the extent to which they serve the TTCs' interests. ${ }^{34}$ Relying on industry data is therefore highly problematic. We, therefore, limit our analysis to examining the agreements and their possible impact on tobacco control, and thus on public health.

\section{FINDINGS}

\section{Lack of transparency}

A key concern is the lack of transparency surrounding the negotiations for, and ongoing management of, the agreements and

Table 1 Characteristics of the agreements between the TTC's and the EU

\begin{tabular}{lllllll}
\hline Company & $\begin{array}{l}\text { Total of annual } \\
\text { payments US\$ }\end{array}$ & Date of signature & End & $\begin{array}{l}\text { Settlement and/or } \\
\text { discharge of legal claims }\end{array}$ & Renewal clause & Termination clause \\
\hline PM & 1 billion & $9 / 7 / 2004$ & $9 / 7 / 2016$ & Yes & Yes & No \\
JTI & 400 million & $14 / 12 / 2007$ & $14 / 12 / 2022$ & Yes & No & Yes \\
BAT & 200 million & $15 / 7 / 2010$ & $15 / 7 / 2030$ & Unknown (see text) & Yes & Yes \\
ITL & 300 million & $27 / 9 / 2010$ & $27 / 9 / 2030$ & Yes & Yes & Yes \\
\hline
\end{tabular}


illicit trade more generally. Also, parts of the agreements are not public. For example, parts of the publically available text of the agreement with ILT have been "omitted due to a request for confidential treatment". ${ }^{35}$ Access to document requests reveal that the correspondence between the European Anti-Fraud Office (OLAF) and the four tobacco manufacturers amounts to tens of thousands of documents, and that OLAF has attended numerous meetings with PMI, JTI, BAT and ITL as part of the agreements. ${ }^{36}$ Yet, not only is there no comprehensive list of these documents, ${ }^{36}$ but requests for these documents, and related information through parliamentary questions and access to documents requests, are often refused on the basis of confidentiality. ${ }^{36-38}$ For example, a parliamentary question could not obtain information on the seizure payments for one of the important contraband brands, Classic, an ITL brand, ${ }^{39}$ which was in 2008 the third most seized cigarette brand in the EU. ${ }^{40}$ The European Commission stated that no information could be provided due to "the rules governing the treatment of confidential information (...)". ${ }^{39} \mathrm{~A}$ freedom of information request on the PMI tracking and tracing system, Codentify, revealed that between January 2008 and November 2011, there were 17 documents of correspondence between OLAF and PMI on this subject. Ten documents were not made public because their disclosure could harm the interests of the Commission during the FCTC negotiations, and "OLAF's relations with companies potentially involved in the possible implementation of tracking and tracing systems". ${ }^{37}$ It remains unclear how the release of documents in 2012 could harm the Commission's negotiating position as the consensus on tracking and tracing systems through the WHO FCTC's Illicit Trade Protocol was reached in March 2010. ${ }^{41}$ Further, this consensus was that the control of tracking and tracing should remain under control of governments and not be delegated to the tobacco industry ( $\$ 2$ and $\$ 10$ of the article 8 of the Illicit trade Protocol), raising serious concerns about the Commission's response. ${ }^{42}$

\section{Inadequate deterrent}

The seizure-based payments are the agreements' main mechanism for deterring the TTCs from further involvement in the illicit cigarette trade by punishing them each time there is a large seizure of their cigarettes. This should also allow EU Member States to recover the taxes lost. Cigarettes are highly taxed products and OLAF estimates that, on average, a container with 10 million cigarettes represents 2 million EURO of lost tax revenue. ${ }^{43}$

Information on seizure payments is not made public but was obtained via access to documents legislation (table 2). ${ }^{38}$ In the period 2004-2012, a total of $€ 70,728,624$ (around US\$ 100 million) in seizure payments was made by PMI, JTI and ITL, or, on average, $€ 8.3$ million annually. BAT has made no seizure payments to date. ${ }^{38}$ In 2012, only $€ 4.1$ million was paid in seizure payments. ${ }^{38}$ This means that the seizure payments were made for approximately 20 million seized cigarettes ${ }^{43}$ just $0.5 \%$ of the 3.8 billion cigarettes seized in the EU in 2012. ${ }^{2}$

These payments represent a tiny fraction of the revenue lost from cigarette smuggling. Based on seizure data in the period 2005-2011, OLAF estimates the financial losses due to illicit cigarette trade at $€ 10$ billion annually in the EU. ${ }^{1}$ The $€ 8.3$ million average annual seizure payments are only $0.08 \%$ of those estimated losses.

There are two main reasons these seizure payments are so small. First, only large seizures qualify for payments, and since the agreements were reached, the modus operandi of cigarette smuggling in Europe has changed. While very large consignments of illicit cigarettes dominated at the time when the agreements were negotiated, most illicit cigarette seizures now consist of substantially smaller consignments. This trend has been confirmed by the World Customs Organization in its 2013 illicit trade report. ${ }^{44}$ In Poland, the country with the highest level of cigarette seizures in the EU, the average seizure in 2011 was around 5200 cigarettes, and for certain brands, such as BAT's Viceroy, the average seizure amount was even lower: 1615 cigarettes. ${ }^{45}$ This means that the threshold of 50000 cigarettes needed to recover taxes and duties lost has become increasingly difficult to meet. The shifting nature of illicit trade has been even recognised by BAT when it agreed to a lower qualifying threshold of 7500 cigarettes in its 1 August 2014 agreement. ${ }^{46}$ However, this new threshold still remains higher than, for instance, the average seizure in Poland, and is therefore not likely to be effective.

Second, payments only apply to genuine TTC cigarettes and not counterfeits, and yet customs officials rely on the industry to determine whether cigarettes are counterfeit (not eligible for seizure-based payments) or genuine (eligible for the payments). This provides a motivation and opportunity for TTCs to claim that the seized cigarettes are counterfeit. According to the agreements, the relevant manufacturer is entitled to examine the seized cigarettes, and send a report to OLAF. If the manufacturer concludes that the cigarettes are counterfeit, the report must contain documentation and examination results demonstrating that conclusion. ${ }^{4}$ If OLAF, or any participating Member State, disagree with the conclusion that the seized cigarettes are counterfeit, the matter is referred to an independent laboratory, designated by mutual agreement of the parties, for final determination. ${ }^{4}$ Since the first agreement came into effect, until 31 October 2013, the seized cigarettes have never been analysed by an independent laboratory and all determination has instead been based on examinations by the TTCs. ${ }^{47}$ During this period, Member States submitted a total of 6,261 seizure notices (for seizures of more than 50000 cigarettes) under the agreements. Out of the total number of seized cigarettes, 3.2 billion $(78 \%)$ were claimed to be counterfeit cigarettes. ${ }^{47}$ Among seized cigarettes of PMI's brands, PMI claimed that $92 \%$ of them were counterfeit cigarettes in $2011 .^{48}$ Yet this very high level of counterfeit cigarettes among seizures is inconsistent with the industry's own estimates of counterfeits on the illicit market. PMI's estimate for the illicit cigarette market globally is that only $1 \%$ was counterfeit in $2012 .{ }^{49}$ For the EU market, a PMI-commissioned study states that $16 \%$ of illicit PM cigarettes consumed in the EU were counterfeit in $2011 .{ }^{48}$ Thus, the industry-estimated prevalence of counterfeits among seized cigarettes is almost six times higher than the prevalence of counterfeits among consumed cigarettes. This would imply that seizure data are unrepresentative of the nature of the illicit market. There are two potential reasons for this. One could be that large seizures are more likely to contain counterfeit than genuine TTC products (and therefore under-represent the real nature of the illicit market in Europe). The other is that TTCs are classifying too many illicit cigarettes as counterfeit in large seizures. Either way, it is clear that the seizure payments do not reflect the size of the illicit market attributable to the TTCs' genuine products.

\section{The industry's tracking and tracing system}

Obliged by the agreements to implement a tracking and tracing system, the TTCs developed their own system, named Codentify. The effectiveness of this system has previously been assessed. It has been found that the industry's system does not meet requirements outlined in Article 8 of the FCTC's protocol 
on illicit trade, ${ }^{50}$ which defines that the tracking and tracing system must be "controlled by the Party" ${ }^{51}$ In addition, the industry-managed tracking and tracing obligation has recently lost its significance due to an EU tracking and tracing system established in Articles 15 and 16 of the Tobacco Products Directive 2014/40/EU of 3 April 2014. ${ }^{52}$ The new Directive introduces an EU-wide tracking and tracing system for the legal supply chain, and visible and invisible security features (eg, holograms) that should facilitate law enforcement, and help authorities and consumers detect illicit tobacco products.

\section{Has TTC involvement in illicit cigarette trade declined or ceased since the agreements between the EU and the TTCs were reached?}

The intention of the agreements was to crack down on smuggling and put in place what it called a "zero tolerance policy" toward illicit shipments. ${ }^{53}$ Yet several reports indicate that the TTC's have remained involved in the trade since their deals were reached. Investigative journalists obtained internal JTI records from whistle-blowers indicating that the company remained involved in the illicit trade and had been less than compliant with the EU agreement. ${ }^{53}{ }^{54}$ OLAF has been officially investigating this case since December $2011,{ }^{55}$ but has yet to make a public statement or come to a conclusion. Other sources point to the TTC's continued complicity in cigarette smuggling to and through Bulgaria between 2000 and 2010, again, after its agreement was reached. ${ }^{56}$ PMI data in 2011 indicate that $21 \%$ of all illicit cigarettes in the EU are PMI's own genuine brands. ${ }^{48}$ At best, this indicates PMI's failure to secure its supply chain as the agreement envisaged. Concerns have been raised about the cigarette brand Classic, produced by Imperial Tobacco, Ukraine, and one of the most seized cigarette brands in the EU in $2008,{ }^{40}$ particularly in light of evidence that the TTCs have been over-producing cigarettes in Ukraine in the knowledge they would enter the illicit market. ${ }^{57}$ In 2014, BAT was fined $£ 650000$ ( $\$ 1 \mathrm{~m} ; € 820 \mathrm{k}$ ) by UK tax authorities for oversupplying its products to Belgium. ${ }^{58}$

\section{What impact has the collaborative approach outlined in the agreements had on tobacco control more broadly?}

A key element of the agreements is that they establish extensive systems of cooperation between the manufacturers, the EU and Member States, an element of the agreements that TTCs have heavily emphasised. ${ }^{59}{ }^{60}$ It is noteworthy that the agreements were reached at a time the TTCs were increasingly being excluded from the policy arena via article 5.3 of the FCTC, which was adopted in 2003 with Guidelines for Article 5.3 agreed in November 2008. ${ }^{61}$ Illicit tobacco provided a perfect opportunity for the TTCs, despite their inauspicious history, to signal shared concerns with policy makers and convince authorities that they were acceptable partners in addressing a trade in which they had previously been complicit. ${ }^{62}$ The potential danger of this collaborative approach threatening tobacco control if norms of collaboration in illicit reached into other areas of tobacco control has previously been raised. ${ }^{62}$ Those threats have been particularly apparent during the revision of the EU Tobacco Products Directive. ${ }^{63}{ }^{64}$ Michel Petite, the Director-General of the European Commission's legal service at the time the first two agreements were negotiated, who played a key role in such efforts, now works for PMI in his new position at legal firm Clifford Chance. ${ }^{63}$ The normalisation of relationships between the TTCs and EU public officials is further illustrated by the nomination of Michel Petite as chair of the EU Commission's Ad hoc Ethical Committee in 2009 and 2012. ${ }^{65}$
The close relationship between OLAF and the TTCs, indicated through the documents outlined above, raises questions, given the concerns about OLAF's role in the scandal surrounding the resignation of Health Commissioner John Dalli, ${ }^{66}{ }^{67}$ the lack of progress of OLAF's investigation into JTI's alleged ongoing involvement in illicit trade, ${ }^{55}$ and OLAF's apparent willingness to involve TTCs in the implementation of tracking and tracing systems under the FCTC's Illicit Trade Protocol, contrary to the protocol itself. ${ }^{37}$

A further concern is that the TTCs appear to have used the agreements with the EU, which are heavily promoted on their websites, ${ }^{68}{ }^{69}$ to negotiate an increasing number of similar agreements nationally and internationally. ${ }^{70}$ In 2011, PMI and INTERPOL, the world's largest police organisation, agreed on a deal in which PMI donated $€ 15$ million to fund a global initiative against illicit goods trafficking, ${ }^{71}$ which would promote PMI's Codentify system. ${ }^{50}$

\section{DISCUSSION}

While limited by the fundamental lack of transparency in this area, our analysis suggests that the agreements have served largely to secure the TTCs interests, reinforced cooperation between the manufacturers, the EU and Member States, and are threatening progress in tobacco control. The seizure payments are paltry and are a wholly inadequate deterrent to TTC involvement in illicit trade. The intention of the seizure-based payments to deter the tobacco industry from further involvement in the illicit cigarette trade has failed because the agreements contain too many loopholes. The industry has both the incentive and opportunity to classify seized cigarettes as counterfeit; and, despite the nature of cigarette smuggling having changed from large to small consignments, seizure payments are due only on large consignments. Further, even the tobacco industry's own data suggest that seizure data (which are based only on large seizures) significantly under-represent the proportion of genuine TTC brands in the illicit market. Consequently, the payments provide no incentives to stop cigarette smuggling and the recovered value of taxes is minimal.

Growing evidence indicates that, despite the agreements, the TTCs remain involved in the illicit trade or are, at best, failing to secure their supply chains as required by the agreements. The agreements instead appear to be part of the TTCs' strategy to establish alliances and partnerships with authorities at the national and international levels to position the tobacco industry as part of the solution to the illicit tobacco trade. By establishing extensive yet opaque collaboration between the TTCs and the Commission, the agreements threaten tobacco control within the EU. By enabling the industry to promote the agreements as an effective model of collaboration, they are also threatening tobacco control internationally. For this reason, many parties to the FCTC were opposed to the inclusion of "legally binding and enforceable agreements" in the text of the draft protocol during the last round of the negotiations of the illicit trade protocol in 2012. ${ }^{72}$

The agreements are also not in line with Article 5.3 of the WHO's Framework Convention on Tobacco Control (FCTC), which all $28 \mathrm{EU}$ countries and the EU have ratified, requiring that "in setting and implementing their public health policies with respect to tobacco control, parties shall act to protect these policies from commercial and other vested interests of the tobacco industry in accordance with national law". The EU's contradictory approach to Article 5.3 and industry collaboration is illustrated by its opinion, expressed at the Fifth and Sixth Conference of the Parties to the FCTC in November $2012^{73}$ 
and October $2014,{ }^{74}$ that INTERPOL should not to be granted an observer status since it received funding from the tobacco industry. Yet a similar relationship exists between the EU and the tobacco industry: with no linked legal action to prompt a deal, the EU accepted $\$ 500$ million ( $€ 400$ million) from BAT and ITL, 26 times larger than PMI's donation to INTERPOL.

In three of the four agreements, the tobacco companies have the right to terminate the monetary payments if there are significant failures of their "reasonable expectations" as to their benefits under the agreements. ${ }^{3}$ No definition of "reasonable expectations" is given publicly and an independent legal opinion notes that "because these expectations are to be assessed by reference to documents, correspondence and agreements which are not publicly available, the breadth of the circumstances in which the EU and Member States might risk termination by the companies cannot be determined." ${ }^{3}$ We believe that there are significant failures of "reasonable expectations" of the public health community with respect to these agreements.

The tracking and tracing obligations in the agreements lost their significance when the EU adopted its Tobacco Products Directive 2014/40/EU, with an EU-wide tracking and tracing system foreseen in Articles 15 and 16.

The EU has already begun its negotiations with PMI to possibly extend its 2004 agreement, while at the same time PMI is challenging the 2014 Tobacco Products Directive in the EU Court of Justice. ${ }^{75}$ We conclude that the agreements have little or no added value and conflict with the article 5.3 of the WHO FCTC. The EU was correct when it expressed a disapproval about the relationship between INTERPOL and PMI and confirmed publicly that "the interests of the tobacco industry are fundamentally opposed to public health" ${ }^{73}$ It should apply the same standard to its own deal with TTCs. Our evidence suggests the EU should not extend its agreement with PMI and, if legally possible, should end the agreements with the other three tobacco companies.

\section{What this paper adds}

- The involvement of the tobacco industry in cigarette smuggling, both direct and indirect, has been well documented. Governments have addressed this type of tax evasion in different ways, including by signing agreements with the tobacco industry to control their supply chain. The best known example of such arrangements is between the four major Transnational Tobacco Companies (TTCS) and the European Union (EU). However, there is no comprehensive assessment of the impact of such agreements in the scientific literature, while the tobacco industry continues to promote such agreements globally.

- We used multiple sources to evaluate the agreements between the EU Commission, EU Member States and major tobacco companies. Despite the lack of data and the secrecy surrounding these contracts, the evidence suggests that they are ineffective. Seizure payments, for instance, provide no incentive for the TTCs to end their involvement in cigarette smuggling because the agreements contain too many loopholes and the recovered value of taxes is minimal compared to the financial losses due to illicit cigarette trade.

Acknowledgements The authors thank John Daniel, Francis Thompson and Wendy Yared for their editing comments.
Contributors The nature and content of the paper were discussed at the outset by all the authors. LJ was the project leader and wrote the first draft. All co-authors provided substantive input on the first draft. $A B G$ and MS provided data obtained via freedom of information requests. $A B G$ wrote sections of and $A B G$ and $M S$ edited the paper

Funding $L, M S$ and $H R$ received funding from the European Parliament, Services Order Nr: IP/D/CONT/IC/2013-175. ABG is supported by Grant Number R01CA160695 from the US National Cancer Institute. ABG is a member of the UK Centre for Tobacco and Alcohol Studies (UKCTAS), a UK Centre for Public Health Excellence. Funding to UKCTAS from the British Heart Foundation, Cancer Research UK, the Economic and Social Research Council, the Medical Research Council and the National Institute of Health Research, under the auspices of the UK Clinical Research Collaboration, is gratefully acknowledged. The content is solely the responsibility of the authors and does not necessarily represent the official views of their institutions, including the National Cancer Institute. Funders had no role in study design and the collection, analysis, and interpretation of data and the writing of the article and the decision to submit it for publication.

Competing interests None declared.

Provenance and peer review Not commissioned; externally peer reviewed.

Open Access This is an Open Access article distributed in accordance with the terms of the Creative Commons Attribution (CC BY 4.0) license, which permits others to distribute, remix, adapt and build upon this work, for commercial use, provided the original work is properly cited. See: http://creativecommons.org/ licenses/by/4.0/

\section{REFERENCES}

1 European Commission. Stepping up the fight against cigarette smuggling and other forms of illicit trade in tobacco products - a comprehensive EU strategy. Brussels: European Commission, 2013.

2 Joossens L, Ross H, Stoklosa M. EU policy and illicit tobacco trade: assessing the impacts. Prepared for the European Parliament's Committee on Budgetary Control. Workshop "Cigarette Smuggling" Proceedings. Brussels: European Parliament, 2014. http://www.europarl.europa.eu/document/activities/cont/201401/ 20140116ATT77675/20140116ATT77675EN.pdf (accessed 20 Aug 2014).

3 Heyward M. Legal analysis of the agreements between the European Union, Member States, and multinational tobacco companies. New York, 2010. http:/l www.fctc.org/publications/bulletins/doc_view/451-legal-analysis-of-eu-agreementswith-multinational-tobacco-companies (accessed 14 Dec 2014).

4 European Commission. Working document on the Agreements with the tobacco industry and fight with the illicit tobacco trade. Committee on Budgetary Control. Brussels: Rapporteur: Bart Staes, 2013. http://www.europarl.europa.eu/document/ activities/cont/201406/20140618ATT85484/20140618ATT85484EN.pdf (accessed 14 Dec 2014)

5 European Anti-Fraud Office. Agreements with tobacco manufacturers. 2015. http:// ec.europa.eu/anti_fraud/investigations/eu-revenue/cigarette_smuggling_en.htm (accessed 10 Apr 2015).

6 European Commission. Speaking points of Commissioner Šemeta on Tobacco Agreements. Brussels, 2014. http://ec.europa.eu/commission_2010-2014/semeta/ headlines/speeches/2014/10/speech141007_en.pdf (accessed 14 Dec 2014).

7 Joossens L, Raw M. Cigarette smuggling in Europe: who really benefits? Tob Control 1998;7:66-71.

8 Gilmore $A B$, Fooks G, Drope J, et al. Exposing and addressing tobacco industry conduct in low-income and middle-income countries. Lancet 2015:385:1029-43.

9 Collin J, LeGresley E, MacKenzie R, et al. Complicity in contraband: British American Tobacco and cigarette smuggling in Asia. Tob Control 2004;13:ii104-11.

10 Lee K, Collin J. "Key to the future": British American tobacco and cigarette smuggling in China. PLoS Med 2006:3:e228.

11 LeGresley E, Lee K, Muggli ME, et al. British American Tobacco and the "insidious impact of illicit trade" in cigarettes across Africa. Tob Control 2008;17:339-46.

12 Nakkash R, Lee K. Smuggling as the "key to a combined market": British American Tobacco in Lebanon. Tob Control 2008:17:324-31.

13 Pan American Health Organization. Profits over people. 2002. http://www1.paho. org/English/DD/PUB/profits_over_people.pdf (accessed 14 Dec 2014).

14 Walker Guevara M. The world's most widely smuggled legal substance. Int Consort Investig J 2008. http://www.icij.org/project/tobacco-underground/worlds-mostwidely-smuggled-legal-substance (accessed 14 Dec 2014).

15 Clarke K. Dilemma of a cigarette exporter. Guardian Published Online First: 3 Feb 2000. http://www.theguardian.com/bat/article/0,191288,00.html (accessed 14 Dec 2014)

16 Government of Canada, Canada Revenue Agency. Comprehensive settlement agreements with tobacco companies. 2008. http://www.cra-arc.gc.ca/gncy/tbcc/ menu-eng.html (accessed 5 Apr 2015).

17 Buddle C. Tobacco chief guilty in $\$ 33 \mathrm{~m}$ bribes case. South China Morning Post, 1998. 
18 Drew C. RJR Nabisco Unit Admits Smuggling. N. Y. Times, 1998. http://www. nytimes.com/1998/12/23/nyregion/rj-nabisco-unit-admits-smuggling.html (accessed 14 Dec 2014).

19 Canada Revenue Agency. Federal and provincial governments reach landmark settlement with tobacco companies. Quebec, 2008. http://www.marketwired.com/ press-release/federal-and-provincial-governments-reach-landmark-settlement-withtobacco-companies-884894.htm (accessed 14 Dec 2014).

20 Government of Canada Launches US Legal Action In Major Tobacco Smuggling Operation. PRNewswire Published Online First: 21 December 1999. http://www. riskworld.com/pressrel/1999/PR99a248.htm (accessed 14 Dec 2014).

21 Beelman M. Philip Morris accused of smuggling, money-laundering conspiracy in racketeering lawsuit. Int Consort Investig J 2000. http://www.icij.org/node/460/ philip-morris-accused-smuggling-money-laundering-conspiracy-racketeering-lawsuit (accessed 14 Dec 2014).

22 ASH. Racketeering legal action (RICO) against tobacco companies for smuggling. 2002. http://www.ash.org.uk/files/documents/ASH_578.pdf (accessed 14 Dec 2014).

23 Joossens L, Raw M. Progress in combating cigarette smuggling: controlling the supply chain. Tob Control 2008;17:399-404.

24 Tomlinson J, Kellett-Bowman E. Committee of Inquiry into the Community Transit System: Final Report and Recommendations v. 1. Luxembourg: European Parliament, 1997.

25 US District Court. European Community complaint against Philip Morris, RJ Reynolds and Japan Tobacco. New York: United States District Court, Eastern District of New York, 2000. http://uniset.ca/other/cs6/150FSupp2d456.html (accessed 5 Apr 2015)

26 Italy backs lawsuit against US tobacco giants. Reuters 6 November 2000.

27 European Community v. RJR. United States District Court, Eastern District of New York. 2002. http://archive.tobacco.org/resources/Documents/021030ecvrj.html (accessed 14 Dec 2014).

28 Mr. Bush and Tobacco. Wash Post 25 Nov 2002, p A14

29 2nd U.S. Circuit Court of Appeals. European Community v. RJR Nabisco Inc, et al No. 11-2475. 2014. http://caselaw.findlaw.com/us-2nd-circuit/1664121.html (accessed 3 Apr 2015).

30 HM Revenue and Customs. Government and industry take a significant step in the fight against tobacco smuggling. 2010. http://www.wired-gov.net/wg/wg-news-1. nsf/0/568F1E6CCOD0AFE3802577610044AOFA?OpenDocument (accessed 14 Dec 2014).

31 European Commission Press Release Database. Under the anti-contraband and anticounterfeit agreement: the European community and 10 member states agree the distribution of approximately 1 billion USD. Brussels: Payments by Philip Morris International, inc., 2006. http://europa.eu/rapid/press-release_IP-06-1314_en.htm (accessed 15 Dec 2014).

32 Philip Morris International Inc., Philip Morris Products Inc., Philip Morris Duty Free Inc., et al. Modification agreement concerning eligibility of new Member States for supplemental payment and related matters. 2012. http://ec.europa.eu/anti_fraud/ documents/cigarette-smugg-2004/pmi_modification_agreement_2014_en.pdf (accessed 5 Apr 2015).

33 KPMG. Project Star 2012 Results. 2013. http://www.pmi.com/eng/media_center/ media_kit/Documents/Project_Star_2012_Final_Report.pdf (accessed 18 Nov 2013)

34 Gilmore $A B$, Rowell A, Gallus $S$, et al. Towards a greater understanding of the illicit tobacco trade in Europe: a review of the PMI funded "Project Star" report. Tob Control 2014;23:e51-61.

35 Imperial Tobacco Limited, European Commission, Member States. Co-operation Agreement. 2010. http://ec.europa.eu/anti_fraud/documents/cigarette_smug/2010_i/ agreement_sept_2010.pdf (accessed 6 Apr 2015).

36 European Anti-Fraud Office. Request for access to documents of 14 November 2011 by Anna Gilmore. Brussels.

37 European Anti-Fraud Office. Request for access to documents of 16 November 2011 by Evelyne Lubbers. Brussels.

38 European Anti-Fraud Office. Request for access to documents of 8 March 2013 by Anna Gilmore. Brussels.

39 European Parliament. Answer given by Mr Semeta on behalf of the Commission. E-012453/2013. 2013. http://www. europarl.europa.eu/sides/getAllAnswers.do? reference $=\mathrm{E}-2013-012453$ \&language $=E N$ (accessed 10 Apr 2015).

40 Walton I. Combating illicit and counterfeit cigarettes: the elements of the problem. Brussels: ITIC, 2009.

41 FCTC. Report of the Chairperson of the Intergovernmental Negotiating Body on a Protocol on Illicit Trade in Tobacco Products to the fourth session of the Conference of the Parties. Uruguay, 2010. http://apps.who.int/gb/fctc/PDF/cop4/FCTC_COP4_4en.pdf (accessed 15 Dec 2014).

42 World Health Organization. Protocol to eliminate Illicit Trade in Tobacco Products. 2013. http://apps.who.int/iris/bitstream/10665/80873/1/9789241505246_eng.pdf (accessed 15 Dec 2014)

43 Action on Smoking and Health. All Party Parliamentary Group on Smoking and Health. Inquiry into the illicit trade in tobacco products. Evidence to the Inquiry provided by Mr Austin Rowan, Advisor to OLAF. 2013. https://www.newcastle.gov. uk/sites/drupalncc.newcastle.gov.uk/files/wwwfileroot/business/trading_standards/ appgillicit20131_compressed.pdf (accessed 15 Dec 2014).

44 World Customs Organization. Illicit Trade Report 2013. 2014. http://www.wcoomd. org/en/topics/enforcement-and-compliance/activities-and-programmes/ /media/WCO/ Public/Global/PDF/Topics/Enforcement\%20and\%20Compliance/Activities\%20and\% 20Programmes/llicit\%20Trade\%20Report\%202012/ILLICIT\%202013\%20-\%20EN LR2.ashx (accessed 15 Dec 2014).

45 Czyzowicz W. The nature of illicit trade in Tobacco and Alcohol products on the Eastern border. Warsaw: Customs book Library, 2013.

46 Belhomme B. Letter from British American Tobacco to Mr. Giovanni Kessler from the European Anti-Fraud Office (OLAF), Ref. Ares(2014)2556161-01/08/2014. 2014. http://ec.europa.eu/anti fraud/documents/cigarette_smug/bat_agreement 01082014_en.pdf (accessed 5 Apr 2015).

47 European Parliament. Answer given by Mr Semeta on behalf of the Commission. E-012454/2013. 2014. http://www.europarl.europa.eu/sides/getAllAnswers.do? reference $=\mathrm{E}-2013-012454$ \&language $=\mathrm{EN}$ (accessed $10 \mathrm{Apr}$ 2015).

48 KPMG. Project Star 2011 Results. 2012. http://www.pmi.com/eng/tobacco_ regulation/illicit_trade/documents/project\%20star\%202011\%20results.pdf (accessed 1 Jan 2014).

49 Calantzopoulos A. Presentation delivered at Morgan Stanley Conference, NY. Slide 43. 2013

50 Joossens L, Gilmore AB. The transnational tobacco companies' strategy to promote Codentify, their inadequate tracking and tracing standard. Tob Control 2014;23(e1): e3-6.

51 FCTC. 6th Conference of the Parties to the WHO Framework Convention. Secretariat study of the basic requirements of the tracking and tracing regime to be established in accordance with Article 8 of the Protocol to Eliminate Illicit Trade in Tobacco Products. Executive Summary, White Paper. Moscow: 2014

52 European Parliament and the Council of the European Union. Directive 2014/40/EU of the European Parliament and the Council of 3 April 2014 on the approximation of the laws, regulations and administrative provisions of the Member States converning the manufacture, presentation and sale of tobacco and related products and repealing Directive 2001/37/EC. 2014. http://ec.europa.eu/health/tobacco/docs/ dir_201440_en.pdf (accessed 28 Aug 2014).

53 OCCRP. Big Trouble at Big Tobacco. 2011. https://reportingproject.net/troubles with_big_tobaccol (accessed 15 Dec 2014).

54 Solomon J. EU Probes Cigarette Deal That May Have Aided Syria. The Wall Street Journal 2012. http://www.wsj.com/articles/SB10000872396390444 233104577595221203321922 (accessed 15 May 2015).

55 European Parliament. Answer given by Mr Semeta on behalf of the Commission. E-007681/2013. 2013. http://www.europarl.europa.eu/sides/getAllAnswers.do? reference $=\mathrm{E}-2013-007681$ \&language $=\mathrm{EN}$ (accessed $10 \mathrm{Apr}$ 2015).

56 Skafida V, Silver KE, Rechel BPD, et al. Change in tobacco excise policy in Bulgaria: the role of tobacco industry lobbying and smuggling. Tob Control 23(e1): e75-84.

57 Lavrov V. Ukraine's "lost" cigarettes flood Europe. Cent Public Integr 2009. http:/ www.publicintegrity.org/2009/06/29/6347/ukraine-s-lost-cigarettes-flood-europe (accessed 18 Nov 2013).

58 Doward J. BAT fined for oversupplying tobacco in low-tax European jurisdictions. Observer 2014. http://hereisthecity.com/en-gb/2014/11/16/bat-fined-foroversupplying-tobacco-in-low-tax-european-jurisdic/page/1/ (accessed 15 Dec 2014).

59 British American Tobacco. British American Tobacco signs cooperation agreement with European Union to tackle illicit trade in tobacco. 2010. http://www.bat.com/ group/sites/UK_9D9KCY.nsf/vwPagesWebLive/D087CF2K?opendocument\&SKN=1 (accessed 19 Dec 2014).

60 Imperial Tobacco. Imperial Tobacco and European Union sign co-operation agreement to jointly combat illicit trade in tobacco. 2010. http://www.imperialtobacco.com/index.asp?page $=56$ \&newscategory $=18 \&$ year $=2010 \&$ newsid $=1198$ (accessed 19 Dec 2014).

61 FCTC. Guidelines for implementation of Article 5.3 of the WHO Framework Convention on Tobacco Control on the protection of public health policies with respect to tobacco control from commercial and other vested interests of the tobacco industry. 2008. http://www.who.int/fctc/guidelines/article_5_3.pdf (accessed 19 Dec 2014).

62 Liberman J, Blecher E, Carbajales AR, et al. Opportunities and risks of the proposed FCTC protocol on illicit trade. Tob Control 2011;20:436-8.

63 Peeters S, Costa H, Stuckler D, et al. The revision of the 2014 European tobacco products directive: an analysis of the tobacco industry's attempts to "break the health silo." Tob Control 2016;25:108-17.

64 Costa $\mathrm{H}$, Gilmore $A B$, Peeters $\mathrm{S}$, et al. Quantifying the influence of tobacco industry on EU governance: automated content analysis of the EU Tobacco Products Directive. Tob Control 2014:23:473-8.

65 Katzemich N. Complaint to the European Ombudsman on behalf of Corporate Accountability International and Corporate Europe Observatory. 2013. https://www. lobbycontrol.de/wp-content/uploads/130208-Petite-Ombudsman-Complaint_final1. pdf (accessed 19 Dec 2014).

66 Corporate Europe Observatory. Complaint to the European Ombudsman about failure to implement WHO rules on tobacco lobbying. Brussels, 2014. http:/l 
corporateeurope.org/sites/default/files/attachments/complaint_about_failure_to_ implement_who_rules_re_tobacco_lobbying.pdf (accessed 15 Dec 2014).

67 Bové J, Luneau G. Hold-up à Bruxelles. Les lobbies au coeur de l'Europe. Paris: La Découverte, 2014.

68 Imperial Tobacco. Regulatory engagement. 2014. https://www.imperial-tobacco.com/ index.asp?page $=778$ (accessed 19 Dec 2014).

69 Imperial Tobacco. Illicit trade. 2014. http://www.imperial-tobacco.com/index.asp? page $=934$ (accessed 19 Dec 2014)

70 Malone RE, Bialous SA. WHO FCTC article 5.3: promise but little progress. Tob Control 2014;23:279-80.

71 INTERPOL. INTERPOL targets organized crime with global initiative against trafficking in illicit goods. 2012. http://www.interpol.int/News-and-media/News/ 2012/PR050 (accessed 15 Dec 2014).

72 Conference of the Parties to the WHO Framework Convention on Tobacco Control. Intergovernmental negotiating body on a protocol on illicit trade in tobacco products, Summary records. FCTC/COP/INB-IT/5/REC/1. Geneva: 2012:63-5; 85-87. http://apps.who.int/gb/fctc/PDF/it5/FCTC_COP_INB-IT5_REC1.pdf (accessed 6 Apr 2015).

73 FCTC. Conference of the Parties to the WHO Framework Convention on Tobacco Control. Fifth Session. Verbatim Records of Plenary Meetings. FCTC/COP/5/REC/ 1. Seoul, Republic of Korea, 2012. http://apps.who.int/gb/fctc/PDF/cop5/FCTC_COP5_ REC1_150413_COMPLETE.pdf (accessed 15 Dec 2014).

74 FCTC. Conference of the Parties to the WHO Framework Convention on Tobacco Control. Sixth Session. Verbatim Records of Plenary Meetings. FCTC/COP/6/VR. Moscow, Russian Federation, 2014. http://apps.who.int/gb/fctc/PDF/cop6/FCTC_ COP6_VR_230115.pdf (accessed 10 Apr 2015).

75 Philip Morris International. Philip Morris International Granted Right to Challenge EU's Tobacco Products Directive Before the Court of Justice of the European Union. 2014. http://www.pmi.com/eng/media_center/press_releases/Pages/201411030908. aspx (accessed 5 Apr 2015). 